\title{
Application of Heterogeneous Catalysis in Small-Scale Biomass Combustion Systems
}

\author{
René Bindig, Saad Butt, Ingo Hartmann *, Mirjam Matthes and Christian Thiel \\ DBFZ Deutsches Biomasseforschungszentrum gemeinnützige GmbH, Torgauer Straße 116, \\ Leipzig 04347, Germany; E-Mails: rene.bindig@dbfz.de (R.B.); saad.butt@dbfz.de (S.B.); \\ mirjam.matthes@dbfz.de (M.M.); christian.thiel@dbfz.de (C.T.) \\ * Author to whom correspondence should be addressed; E-Mail: ingo.hartmann@dbfz.de; \\ Tel.: +49-341-2434-541; Fax: +49-341-2434-133.
}

Received: 27 February 2012; in revised form: 14 March 2012 / Accepted: 23 March 2012 / Published: 12 April 2012

\begin{abstract}
Combustion of solid biomass fuels for heat generation is an important renewable energy resource. The major part among biomass combustion applications is being played by small-scale systems like wood log stoves and small wood pellet burners, which account for $75 \%$ of the overall biomass heat production. Despite an environmentally friendly use of renewable energies, incomplete combustion in small-scale systems can lead to the emission of environmental pollutants as well as substances which are hazardous to health. Besides particles of ash and soot, a wide variety of gaseous substances can also be emitted. Among those, polycyclic aromatic hydrocarbons (PAH) and several organic volatile and semi-volatile compounds (VOC) are present. Heterogeneous catalysis is applied for the reduction of various gaseous compounds as well as soot. Some research has been done to examine the application of catalytic converters in small-scale biomass combustion systems. In addition to catalyst selection with respect to complete oxidation of different organic compounds, parameters such as long-term stability and durability under flue gas conditions are considered for use in biomass combustion furnaces. Possible catalytic procedures have been identified for investigation by literature and market research. Experimental studies with two selected oxidation catalysts based on noble metals have been carried out on a wood log stove with a retrofit system. The measurements have been performed under defined conditions based on practical mode of operation. The measurements have shown that the catalytic flue gas treatment is a promising method to reduce carbon monoxide and volatile organic compounds. Even a reduction of particulate matter was observed, although no filtering effect could be detected. Therefore, the oxidation of soot or soot precursors can
\end{abstract}


be assumed. The selected catalysts differed in their activity, depending on the compound to be oxidized. Examinations showed that the knitted wire catalyst showed better activity for the reduction of carbon monoxide, whereas the honeycomb induced a higher reduction of aromatic compounds. The properties of the two catalysts can be combined by integrating both together. The one drawback of the catalyst so far is the deactivation for the conversion of methane.

Keywords: biomass combustion; flue gas treatment; electrostatic precipitation; VOC; PAH; soot; emission reduction

\section{Introduction}

Due to the increase of renewable energy from small-scale biomass combustion, a reduction of flue gas emissions is necessary. Approximately $90 \%$ of renewable heat is generated by combustion of solid biomass fuels, out of which $75 \%$ is contributed by household appliances [1]. Pellet burners for the combustion of wood, as well as other alternative fuels, or manually-loaded fireplaces, release harmful and toxic emissions, which are formed during incomplete combustion. Therefore, the development of emission reduction measures such as catalytic flue gas cleaning is a necessity.

There are various organic compounds originating from biomass combustion furnaces as a result of incomplete combustion or pollutant formation processes. Among them, a large diversity of molecule structures exists, starting with several chain-like hydrocarbons, e.g., alkanes, alkenes as well as aldehydes, up to aromatic compounds like benzene and polycyclic aromatic hydrocarbons (PAH). The latter are considered as soot precursors. Furthermore, the formation of polychlorinated dibenzo-dioxins and -furans $(\mathrm{PCDD} / \mathrm{F})$ is a relevant subject in combustion research and emission reduction development, especially regarding the use of agricultural and alternative biomass fuels with a high ash-content. Emissions of several wood log stoves have been analyzed by our research group. The already published results [2] show high emissions from different kinds of wood log stoves during the start and burnout phase. In addition to gaseous organic compounds, soot and nitrogen oxides should also be reduced in flue gases. Threshold values for carbon monoxide and particulate matter in exhaust gases of small-scale firing systems are defined by the 1st Federal Emission Control Ordinance in Germany. For other compounds, no threshold values exist so far, although they are required due to their harmful properties.

The conversion of the above-mentioned organic substances to carbon dioxide and water can be accomplished by heterogeneous catalysis. Therefore, investigations have to be made about the behavior of solid and often porous catalysts in flue gases as well as reactions of gaseous compounds on the surfaces of solid catalysts.

According to the complex process of heterogeneous catalysis, one can define essential requirements regarding the use of catalysts for total oxidation in biomass combustion furnaces. First of all, a high activity along with a pronounced selectivity towards carbon dioxide is needed for the oxidation of volatile organics, carbon monoxide, and on up to PAHs. Furthermore, the activity for the oxidation of soot is also a desirable attribute and the maintenance of low nitrogen oxide emissions has to be taken 
into account. Moreover, a good thermal and mechanical stability of the catalyst is necessary. Lastly, the catalyst should be insensitive to poisoning, and regeneration should be possible with low energy demand as well as low costs. Taking the described characteristics into account, promising materials can be identified with respect to selected operations. One possibility is the use of supported catalysts with metal alloys (FeNiCrAl) or ceramics (cordierite, silicon carbide) as support. A porous washcoat layer, mostly consisting of $\gamma$-alumina, is added on the support to increase the surface area. In the porous washcoat the catalytic active species are incorporated, e.g., by impregnation. An alternative is the application of bulk or monolithic catalysts, which may consist of metal oxides or mixed metal oxides. Known substances for catalytic oxidation are noble metals: specifically platinum, palladium, ruthenium and rhodium as well as metal oxides, e.g., from copper, manganese, vanadium and tungsten, lanthanum in perovskites or spinel structures. A proper selection of catalytic substances, support and design of catalyst applications is extremely important to achieve the required operation and prevent failure due to poisoning, thermal deactivation, blockage of pores and/or active sites.

In literature, one can find some research projects of other research groups as well as developments in the commercial market, which deal with, and accordingly offer, catalytic emission reduction systems for combustion furnaces. In several papers, the results of investigations for noble metal catalysts are presented. Ahlström-Silversand et al. [3] and Carnö et al. [4] both examined the effect of noble metals compared to metal oxides. The former found that $\mathrm{V}_{2} \mathrm{O}_{5} / \mathrm{CuO}$ is active for soot oxidation and palladium and platinum show good activity for high levels of conversion of volatile organic compounds (VOCs). The catalytic substances were dispersed on a $\gamma$-alumina coated wire mesh. Likewise, Carnö [4] concluded that platinum is more active than manganese and copper oxides on $\gamma$-alumina for oxidation of VOCs. In addition, the higher stability of methane compared to other VOCs, and therefore the necessity of a higher temperature for oxidation, is described on the basis of experimental data. Ferrandon and coworkers [5] investigated metallic monoliths made of iron, chromium and aluminum combined with an alumina washcoat doped with lanthanum. Manganese oxide or manganese oxide mixed with platinum were used as catalytic active substances. To carry out the activity test, a mixture of carbon monoxide, methane and naphthalene was utilized. High concentrations of manganese oxides favored the oxidation of carbon monoxide and naphthalene while lower concentrations showed higher activity for the oxidation of methane.

In Germany, the companies moreCat GmbH and Dr. Pley Environmental offer retrofit devices for emission reduction in stoves. The "Ofenkatalysator" (moreCat $\mathrm{GmbH}$ ) [6] consists of noble metals $(\mathrm{Pd}, \mathrm{Pt})$ dispersed on a metallic swarf support. The needed light-off temperature is $450 \mathrm{~K}$. The "ChimCat" produced by Dr. Pley Environmental has a ceramic support [7]. The catalytic active components are also noble metals, but detailed information is not given. In the USA, the integration of catalysts in the post-combustion chamber is state of the art. For instance, the company, Applied Ceramics, offers a catalyst named "Firecat," consisting of noble metals ( $\mathrm{Pt}, \mathrm{Pd}, \mathrm{Rh}$ ) on a ceramic honeycomb as support [8]. The light-off temperature is about 530 to $570 \mathrm{~K}$. Vermont Castings have a so-called "catalytic stove" in their product line. In the post combustion chamber, a catalyst from Südchemie called "EnviCat" is integrated with noble metals as active species on a ceramic support (honeycomb). Apart from that, a similar catalyst is available from a French company named "Zéro CO Technology", which is composed of noble metals doped with cerium on a ceramic (cordierite) or metallic (FeCr alloy) support. The light-off temperature also lies between 530 and $570 \mathrm{~K}$. Finally, 
there is also a catalytic system for nitrogen oxide reduction combined with particle filtration, which is described by Heidenreich et al. [9]. The equipment from Pall Filtersystems GmbH includes silicon carbide candles with $\mathrm{V}_{2} \mathrm{O}_{5}-\mathrm{WO}_{3}-\mathrm{TiO}_{2}$ catalysts and a mullite membrane layer with a thickness of 150 to $200 \mu \mathrm{m}$. Pilot tests have been carried out at a 3.5 MW biomass combustion plant.

As shown by the examples listed above, noble metals dispersed on $\gamma$-alumina washcoats are frequently applied as catalysts for emission reduction. Metal oxides and mixed metal oxides are also discussed, especially for soot and tar oxidation. Nevertheless, there are still many investigations to be made for the proper use of catalysts in small-scale biomass combustion systems. Precise information about deactivation and poisoning by inorganic trace substances are required and more data about operation in real combustion furnaces is necessary.

For use in firing systems, a long-term operation is needed in terms of ecological, economical and user-friendly aspects. Appropriate solutions have to be found with respect to the design of firing systems to establish the use of catalytic treatment of flue gases from biomass combustion. Beside this, one has to pay attention to several process conditions, for example the temperature range during the burning cycle, flow rate and pressure drop as well as the durability of the materials used. The investigations carried out in our research group focus on the identification of solutions for practical realization using commercially available products. Therefore, the proportion between the costs of the firing system and the catalytic reduction system has to be considered. The aim is the development of a marketable product in the near future. By analyzing various commercially available catalysts, their performance and drawbacks are determined, to rate their applicability for flue gas treatment and to find clues for further catalyst modification or development. To consider the differences of existing furnaces, experiments are performed with different fireplaces and pellet burners. In the following sections, the investigations and results of one selected firing system are presented.

\section{Results and Discussion}

\subsection{Combustion Process and Characteristics of the Examined Wood Log Stove}

Due to the different phases of a burning cycle, the conditions at the catalyst undergo cyclical fluctuations. The burning cycle includes the following phases: heating up, high temperature combustion and smoldering. The data of the reference experiment without catalyst show the characteristic emission curve for combustion processes in fireplaces. As shown in Figure 1 for carbon monoxide (CO) and total hydrocarbons (THC), the highest concentrations of the examined compounds are emitted during the heating up phase after refilling the stove. The peak concentration of $\mathrm{CO}$ is around 16,500 ppm and about 14,000 ppm for THC. After the high temperature combustion phase, where the emissions are comparatively low for CO (250-500 ppm) and THC (50-200 ppm), the smoldering phase follows. An increase of the $\mathrm{CO}$ concentration takes place up to values around $3000 \mathrm{ppm}$. During all burning phases, an excess of oxygen was observed in the flue gas. The oxygen concentration varied between 6 and 18 vol.- $\%$, according to the burning phase, see Figure 2 . Particularly, a reduction of incompletely oxidized carbon emissions was achieved during the heating up and smoldering phases by using catalysts. 
Figure 1. Carbon monoxide (CO) and total hydrocarbon (THC) concentration in the exhaust gas during several burning cycles in the wood log stove used during experimentation.

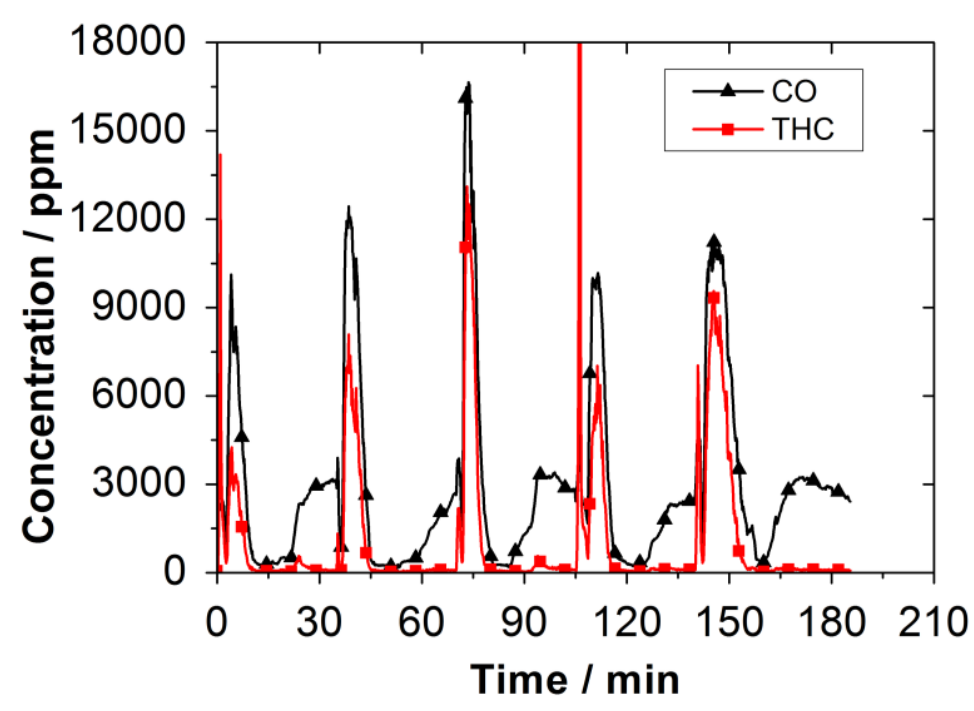

Figure 2. Oxygen concentration and ratio of actual air-fuel ratio to stoichiometric ratio $(\lambda)$ in the exhaust gas during several burning cycles in the wood log stove.

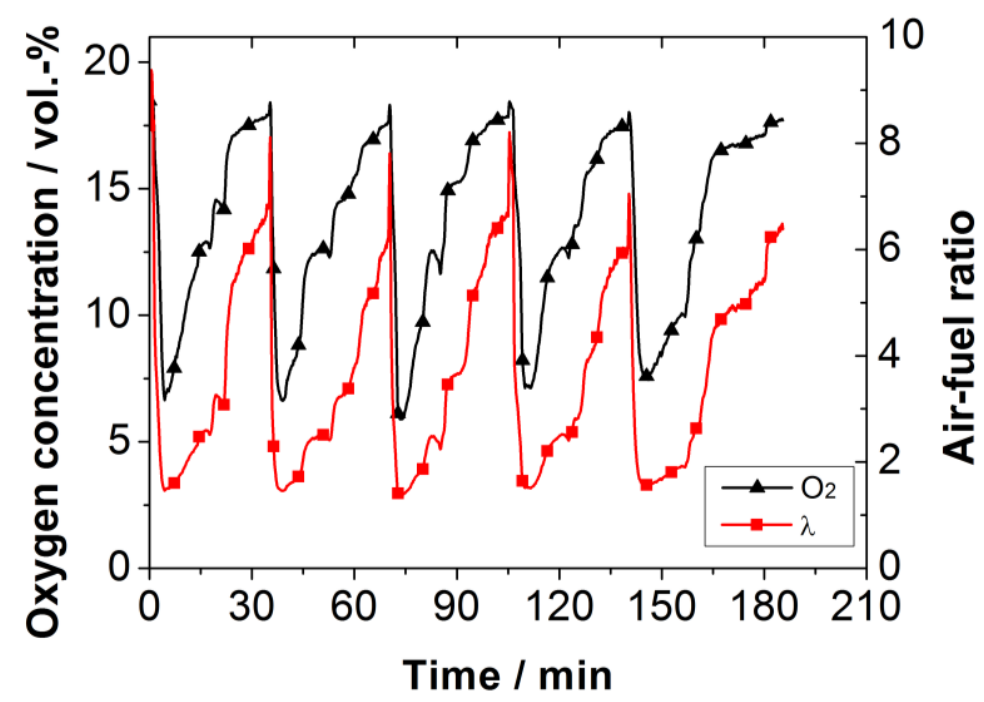

For the experiments described in this paper, neither temperature nor volumetric flow showed any significant differences. Therefore, average values determined from all experiments are presented. The conditions at the catalyst undergo alterations due to the cyclic combustion process. The temperatures at the catalyst vary from 570 to $830 \mathrm{~K}$. The highest temperatures occur during the high temperature combustion phase. Figure 3 shows the temperature curve for five burning cycles. 
Figure 3. Temperature upstream and downstream of the catalyst during several burning cycles in the wood log stove.

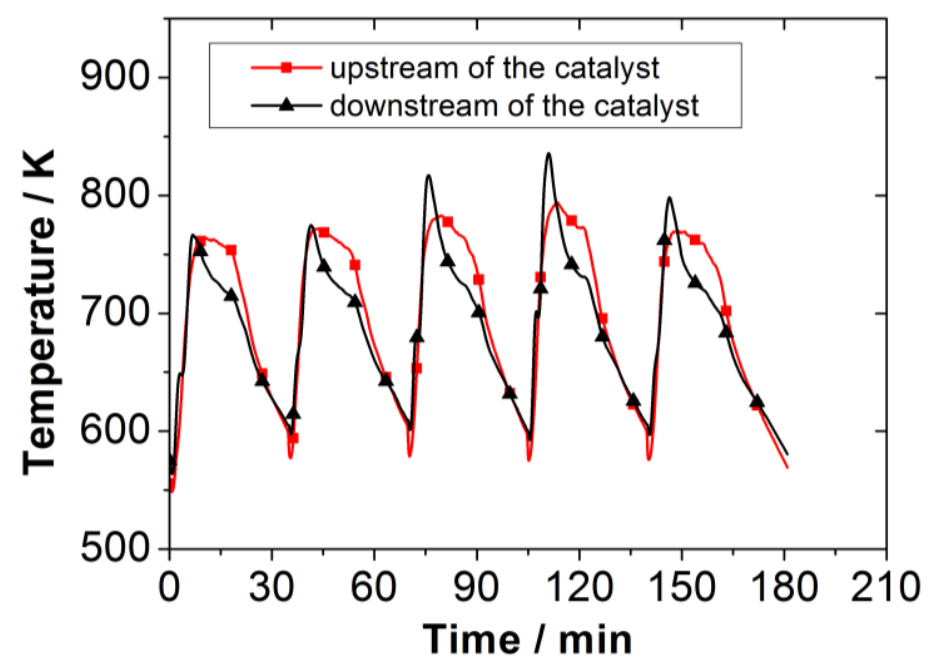

The volumetric flow through the firing system is dependent on the chimney fan, whose power is regulated to achieve a constant negative pressure inside of the combustion chamber, upstream of the catalyst. Therefore, the highest flow occurs during the high temperature combustion phase, when a considerable amount of gas is released. Figure 4 shows the curve of the volumetric flow during five burning cycles. The pressure drop across the catalyst also varies, as it is dependent on the volumetric flow. The residence time of the flue gas in the catalyst fluctuates as presented in Figure 5. For one honeycomb catalyst unit the residence time of the flue gas is between 0.015 and $0.030 \mathrm{~s}$, for two catalyst units the range is between 0.035 and $0.055 \mathrm{~s}$. The volume of the knitted wire catalyst unit is about $85 \%$ of the honeycomb. Accordingly, the residence time is $85 \%$ of the value presented for the honeycomb.

Figure 4. Volumetric flow through the firing system and accordingly through the catalyst in the wood log stove.

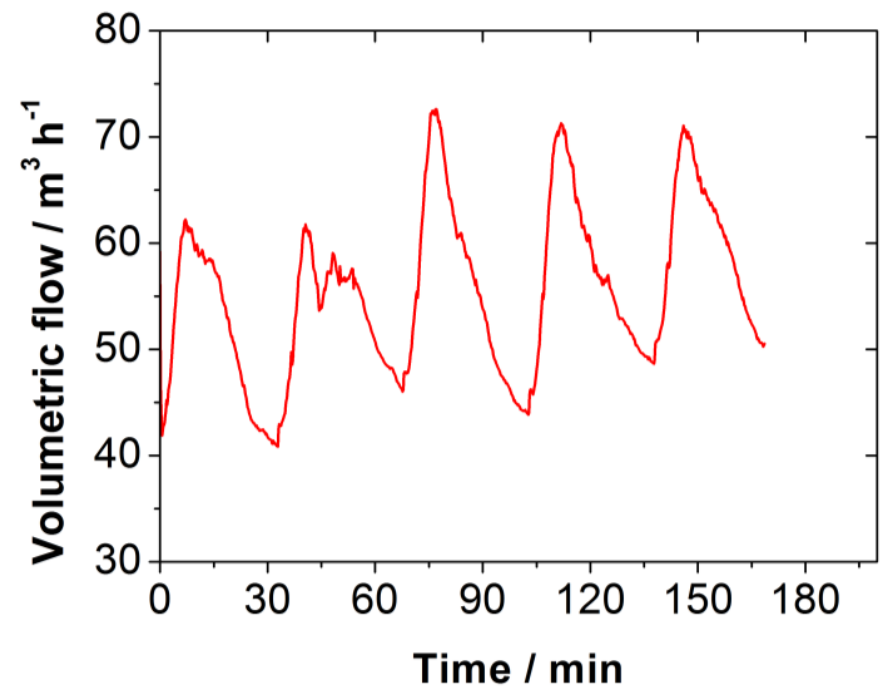


Figure 5. Residence time of the flue gas in the catalyst during operation with one and two catalyst units. (The values are not dependent on the different materials used.)

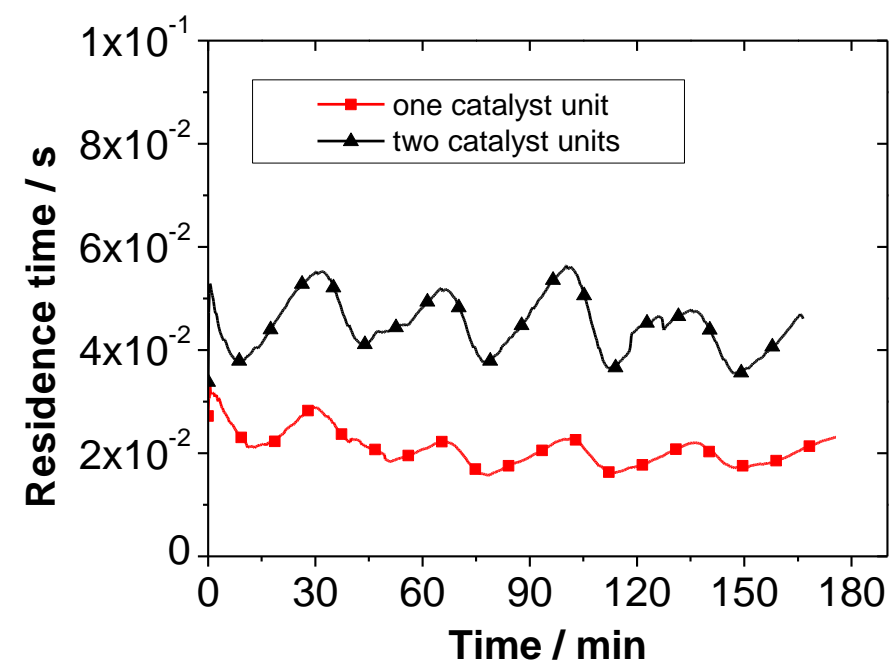

A temperature-dependent conversion or reduction rate analysis is not reasonable so far, because the stove can only operate under transient conditions with fast changes in pollutant concentrations and temperature. As the catalysts were not operated under isothermal conditions, it is not possible to get reliable data with the used experimental setup. Therefore, mean values of five complete burning cycles were calculated for each experiment to analyze the pollutant reduction behavior of the different catalysts under examination. In future experiments, the recording of three-dimensional temperature profiles of catalysts should be carried out. Also, simultaneous gas phase measurements with FTIR are necessary, upstream and downstream of the catalyst. Furthermore, the experimental data should be compared with reactor model simulation.

\subsection{Catalytic Flue Gas Cleaning in a Retrofit System in a Wood Log Stove}

\subsubsection{Activity and Pressure Drop According to Material and Catalyst Volume}

Both tested catalysts, the ceramic honeycomb, as well as the knitted wire catalyst, showed considerable activity for oxidation of organic flue gas components. Both were inserted fresh after manufacturing and delivery without previous usage or conditioning. Indeed, their reactivity differs for the component to be oxidized. The results of the measurements are presented in Figure 6. The knitted wire catalyst unit showed a higher reduction of carbon monoxide and higher formations of nitrogen oxides than the honeycomb catalyst, whereas the reduction of aromatic compounds of $86.3 \%$ was higher for the honeycomb than for the knitted wire $(70.9 \%)$. The reduction of carbon monoxide was $99.5 \%$ using the knitted wire catalyst and $92.6 \%$ using the honeycomb catalyst. The nitrogen oxide concentration was increased to $139.1 \%$ for the knitted wire in relation to the reference experiment and to $110.0 \%$ for the honeycomb. Also, a reduction of $80 \%$ was observed for all measured hydrocarbons. For methane, the reduction was $80.4 \%$ (honeycomb) and $84.5 \%$ (knitted wire); for acetylene it was $94.5 \%$ (honeycomb) and $92.4 \%$ (knitted wire).The reduction of particulate matter (PM) emission is again higher using the knitted wire catalyst. For the knitted wire, the concentration was reduced by $49.9 \%$, and for the honeycomb by $34.3 \%$. Comparing the emission reduction of the 
catalysts, one has to take into account that the residence time is not the same for both, due to their different design. Therefore, the comparison given refers to the use of commercially-available catalytic devices under flue gas conditions and not to the catalytic activity in relation to the same catalytic surface area.

The pressure drop across the honeycomb catalyst is higher than that of the knitted wire catalyst. As both show no increasing trend over several burning cycles (see Figure 7), their use for continuous operation is promising.

Figure 6. Comparison of the concentrations of selected pollutants and of oxygen in the exhaust stream without catalyst and with the two tested catalysts (black bars: without catalyst; red bars: knitted wire catalyst, green bars: honeycomb catalyst; * The measurement unit of the particulate matter concentration is $\mathrm{mg} \mathrm{Nm}^{-3}$ and for all other pollutants ppm).

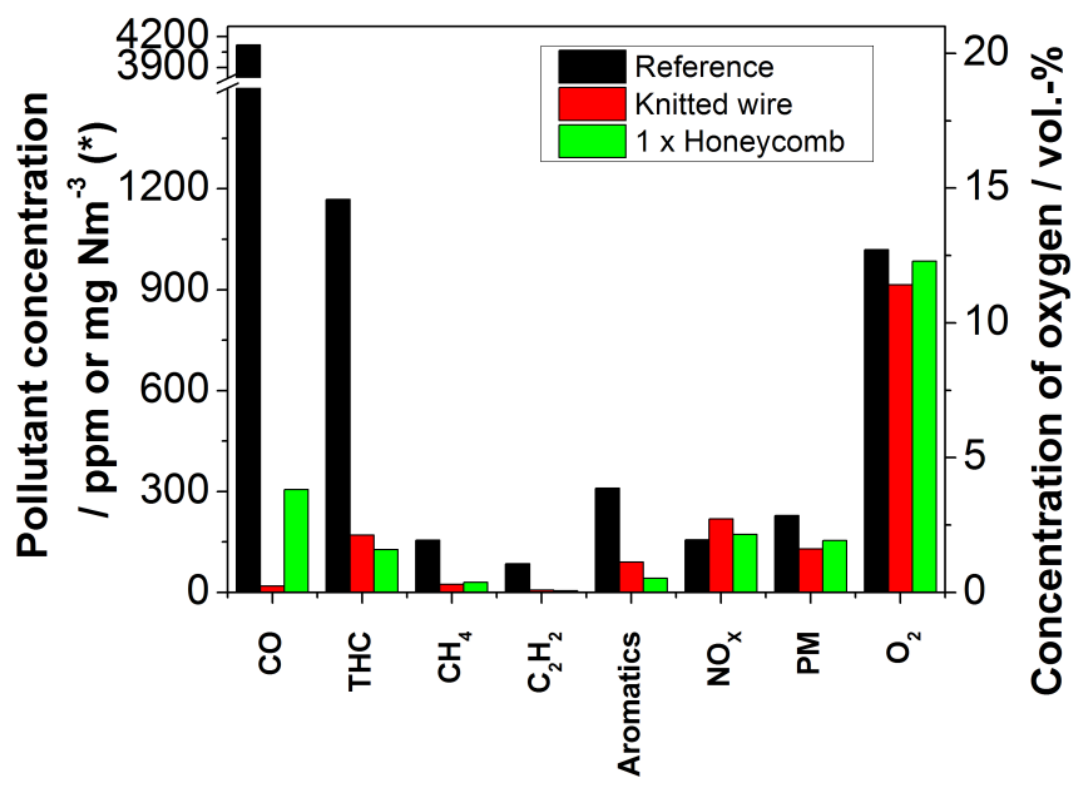

Figure 7. Signal curve and trend (linear fit) for the pressure drop across the catalyst during operation time.

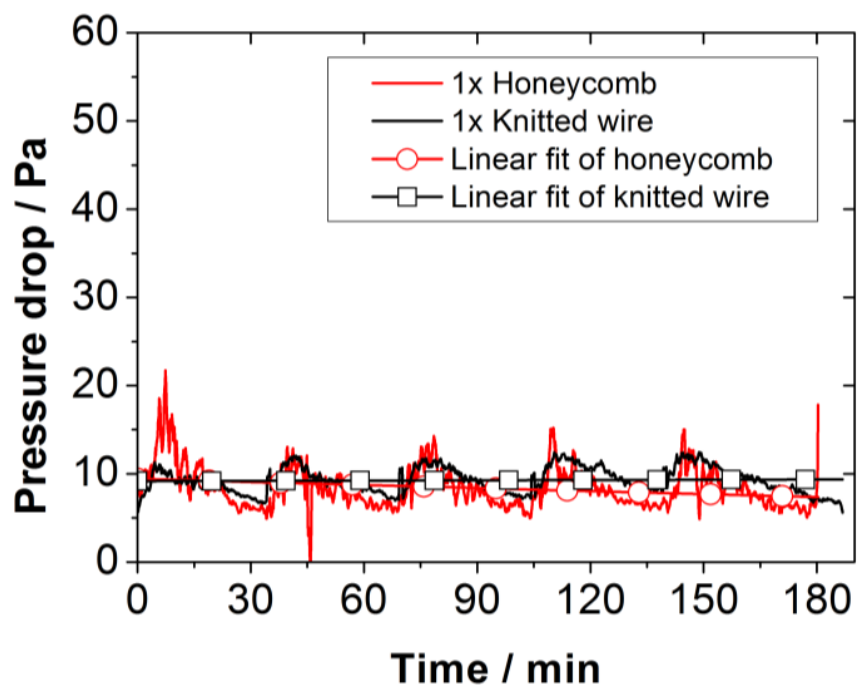


By increasing volume of the honeycomb catalyst, the reduction of gaseous carbonaceous compounds is increased for $\mathrm{CO}$ to $95.3 \%$ and for THC to $90.8 \%$. But at the same time, the concentration of nitrogen oxides is slightly higher with a concentration of $121.7 \%$ in relation to the reference value. For the other investigated carbon compounds (THC, $\mathrm{CH}_{4}, \mathrm{C}_{2} \mathrm{H}_{2}$ and aromatics), only a small change of $1-4 \%$ was observed. The reason for the minor change after inserting a second catalyst compared to the difference between the reference and one catalyst unit might be given in the concentration dependency of the reaction rate. The second catalyst unit had to be placed downstream of the first unit, because of the construction of the retrofit system. Therefore, much lower pollutant concentrations were present in the second unit, obviously leading to a lower reaction rate. The particulate matter emission remains the same. As a result, no significant filter effect is observed for the catalyst. Figure 8 shows the measured emissions, comparing one and two catalyst units. Even though the range of the pressure drop is naturally increased by extension of the volume, see Figure 9, again no upward trend is observed. A secure operation seems possible.

Figure 8. Comparison of the concentrations of selected pollutants and of oxygen in the exhaust stream for one and two catalyst units (black bars: one catalyst unit; red bars: two catalyst units. * The measurement unit of the particulate matter concentration is $\mathrm{mg} \mathrm{Nm}^{-3}$ and for all other pollutants ppm).

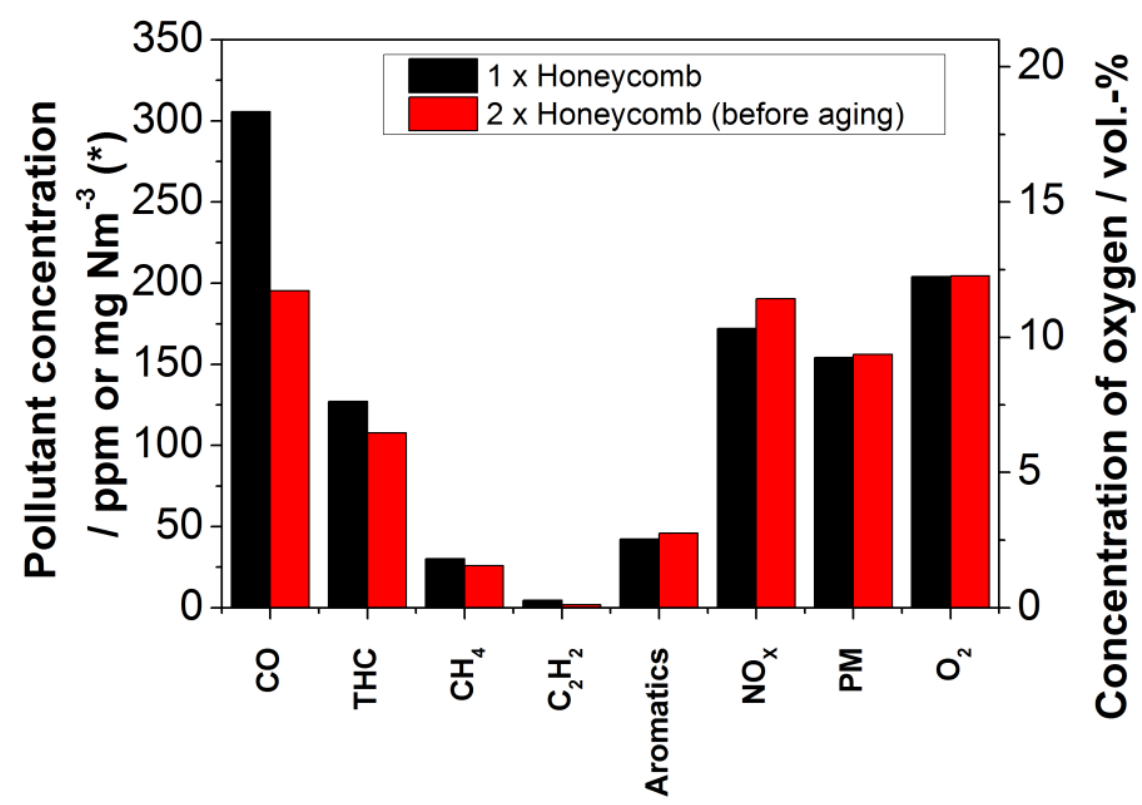


Figure 9. Signal curve and trend (linear fit) for the pressure drop across the one and two honeycomb catalyst units during operation time.

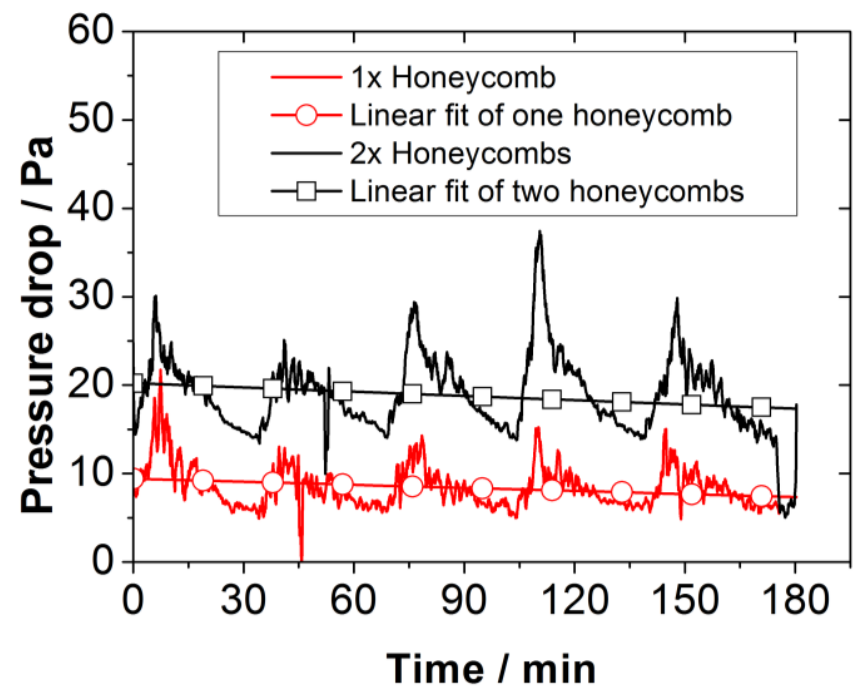

Ozil et al. [10] already studied the efficiency of catalytic processes for the reduction of emissions from small-scale combustion systems. They also used two different kinds of catalysts. One was based on cordierite support and another one on a metallic support (corrugated structure). In addition, the influence of catalyst heating was studied. The cell densities of the catalysts were quite low ( $25 \mathrm{cpsi}$ for the cordierite support and $16 \mathrm{cpsi}$ for the metallic one) to meet the requirement of a low pressure drop. A chimney fan was used in the current study, so catalysts with higher pressure drops could be tested. That is, catalysts with higher cell densities (100 cpsi for the cordierite honeycomb) or made of knitted wires. Furthermore, results concerning the long-term stability of the catalysts or a combination of both were not mentioned in [10]. The emission reductions reported by Ozil et al. [10] were lower (e.g., CO reduction of 80 to $90 \%$ ) compared to the findings in this work (CO reduction > $90 \%$ ). A reason for the differences could be the higher cell densities of the catalysts, i.e., higher catalytic surface area, used in this work.

\subsubsection{Deactivation during Operation}

The comparative measurements of the honeycomb catalyst in the retrofit system showed a slight change in the flue gas concentration of selected pollutants after two performed experiments, according to the routine described in Section 3 (Experimental Section). While the reduction of CO and aromatic compounds is even a little higher after several burning cycles than in the fresh state, the reduction of total hydrocarbons (THC), methane as well as acetylene, and also the formation of nitrogen oxides is lower. The nitrogen oxide concentration is actually $100.8 \%$ and therefore as low as during the reference examinations without catalyst. The results are represented in Figure 10. The major change of carbon emissions was observed for methane, where the reduction was decreased to $67.7 \%$. Again, the pressure drop showed no upward trend during the experiment, even though the range was a little higher than before the two aging experiments. The particulate matter emission is the same before and after the two aging experiments. 
Figure 10. Comparison of the concentrations of selected pollutants and oxygen in the exhaust stream after the catalyst in the fresh state (black bars) and after $16 \mathrm{~h}$ of use (red bars); * The measurement unit of the particulate matter concentration is $\mathrm{mg} \mathrm{Nm}^{-3}$ and for all other pollutants ppm.

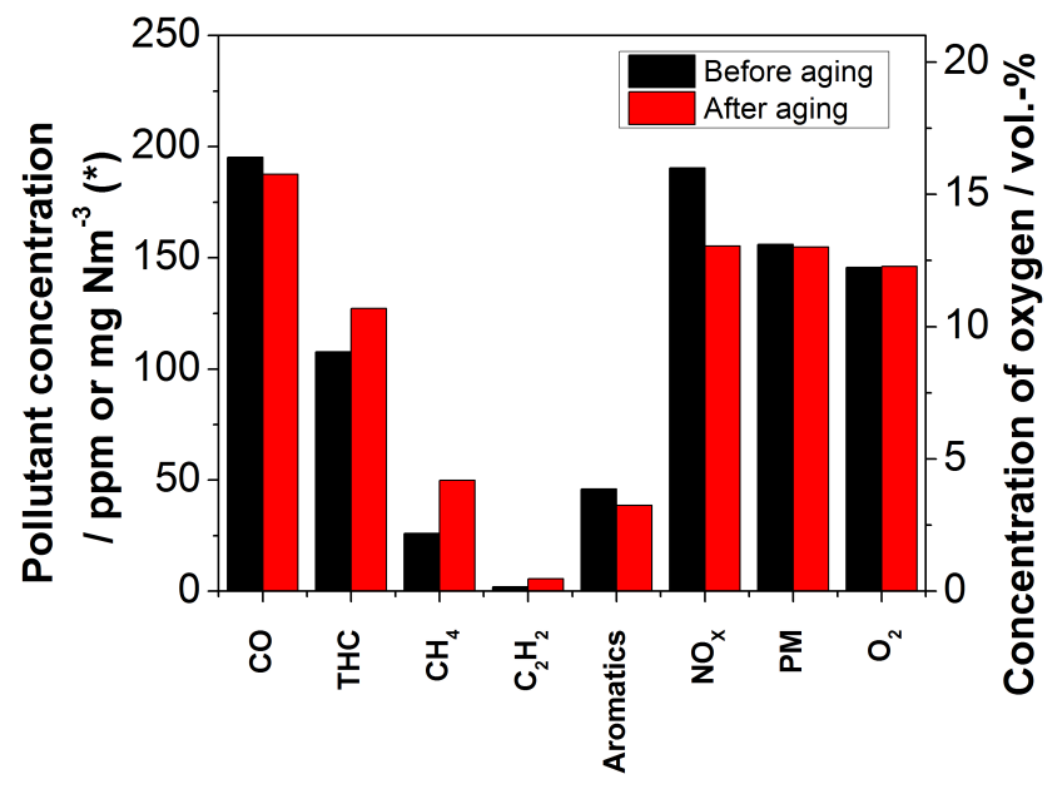

Experiments for the deactivation of the knitted wire catalyst are not carried out yet. The performance is planned when appropriate samples for analysis in the catalyst testing apparatus are received.

\subsubsection{Combination of Honeycomb and Knitted Wire Catalyst}

Because the examined catalysts showed different behavior regarding the measured pollutants, the use of both was assumed to be a good possibility to combine their advantages. Both inserted catalytic devices had already been used in the foregoing experiments as described above. The honeycomb catalyst was placed upstream of the knitted wire catalyst during the experiment. The setup was chosen according to the less flexible form of the honeycomb, which offered a supporting surface for the knitted wire unit. In correlation with the foregoing assumption, the emission values can be attributed to some extent to the catalyst that showed a higher activity when used as a single unit. More precisely, as depicted in Figure 11, the emissions of CO are close to the values of the experiment with the knitted wire catalyst. The reduction is $98.1 \%$ in relation to the reference. The concentrations of THC as well as aromatic compounds are analogous to the experiment with the honeycomb catalyst. A reduction of $89.0 \%$ for THC and $87.3 \%$ for aromatic compounds was observed. The reduction of $93.4 \%$ for acetylene is analog to the values measured at the experiments with the single units. For interpretation of this comparison, one also has to take into account that the catalyst deactivates while using it in the retrofit system. On this basis, the slightly higher methane concentration of the combined catalysts in comparison to the values of the single ones can be explained by the deactivation of the catalysts with respect to methane oxidation. The reduction of $66.5 \%$ for methane is about the same as for the aged honeycomb catalysts. The data for the activity measurements of methane oxidation will be given in the following chapter. 
Figure 11. Comparison of the concentrations of selected pollutants and oxygen in the exhaust stream after the catalyst (black bars: knitted wire catalyst; red bars: honeycomb catalyst, green bars: combination of honeycomb and knitted wire catalyst; * The measurement unit of the particulate matter concentration is $\mathrm{mg} \mathrm{Nm}^{-3}$ and for all other pollutants ppm).

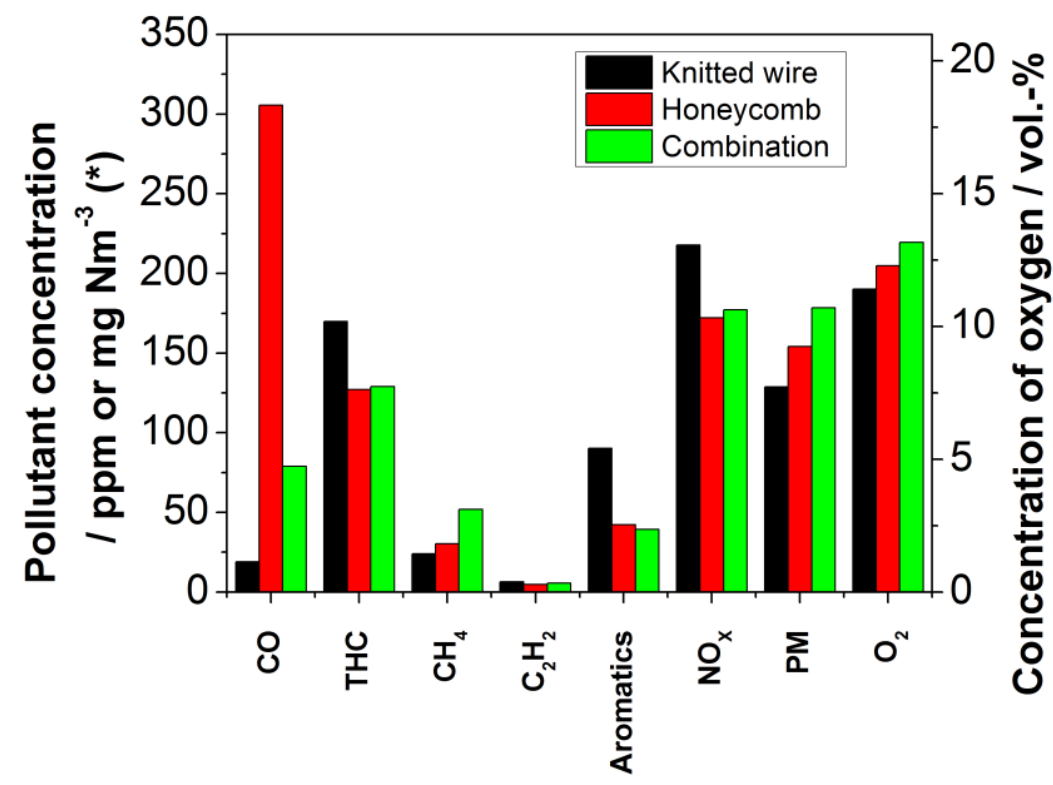

\subsection{Catalytic Activity of Monolithic Catalysts for Methane Oxidation}

By interpretation of the data from the CTA-experiments (catalyst testing apparatus), the deactivation of the honeycomb catalyst was investigated during the use in the retrofit system. Furthermore, a trend for the long-term stability can be observed. While preparing the samples of the knitted wire catalyst and their installation into the CTA, the washcoat of the catalyst was easily removed from the wire by mechanical stress. Therefore, the analysis of the knitted wire catalysts could not be carried out in a reproducible way. Hence, reliable data only exist for the honeycomb catalyst.

The examined honeycomb catalyst was in use for a total time of six experiments (procedure described in Section 3) within the self-constructed retrofit device called RFS-TKI. It was exposed to temperatures between 550 and $800 \mathrm{~K}$ during its use. The temperatures were subjected to strong fluctuations, see Figure 3. Fluctuations of the exhaust gas temperature and highly variable composition of flue gases are typical for manually loaded small-scale firing systems, such as wood log stoves.

The results from the investigation (temperature-conversion curves) of the honeycomb catalyst before and after usage in the retrofit system RFS-TKI are shown in Figure 12. The loss of activity for the oxidation of methane after usage in the retrofit system is obvious. In the fresh state, a methane conversion of $85 \%$ at $800 \mathrm{~K}$ was recorded. After usage in the firing system, the conversion was only $62 \%$ at the same temperature. Given that the concentration of other carbonaceous compounds than methane, like $\mathrm{CO}$ and aromatics, was not higher after several hours of catalyst usage, a selective or specific deactivation can be assumed, which especially affects the catalytic methane oxidation process. 
Figure 12. Illustration of the loss of activity towards the oxidation of methane after usage in the retrofit system RFS-TKI by means of the temperature-conversion behavior.

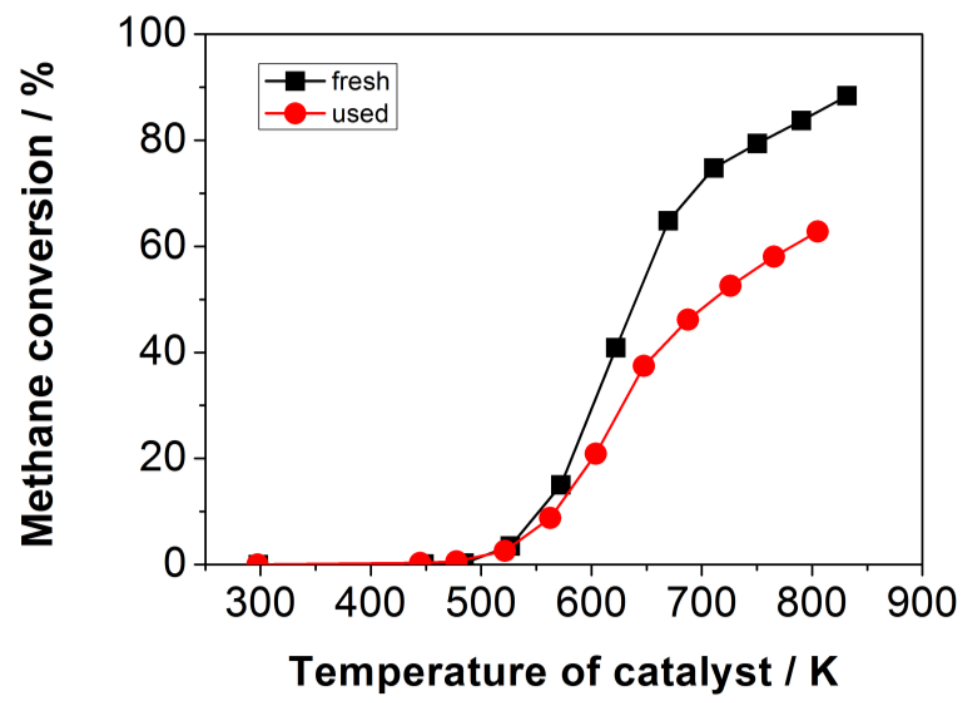

Methane was used as a model flue gas compound, as its stability is known to be high. The critical step for the oxidation of methane is the cracking of the $\mathrm{CH}$-bond. The bonding strength requires high activation energy for the reaction. If total oxidation of methane (see overall reaction below) is achieved by the catalyst, it is likely that a wide range of other carbon compounds can also be oxidized.

$$
\mathrm{CH}_{4}+2 \mathrm{O}_{2} \stackrel{k_{e f f}}{\longrightarrow} \mathrm{CO}_{2}+2 \mathrm{H}_{2} \mathrm{O}
$$

The Arrhenius (Figure 13) plots were calculated from the temperature-conversion curves of both catalyst samples for interpretation of the experimental data. The quantification of the activity of the catalysts was analyzed by determining the pre-exponential factors and the activation energies. To calculate the rate constants $\left(k_{e f f}\right)$ at the different temperatures, the following assumptions were made. The reaction is pseudo first order, because of the high oxygen excess. It is not reversible and takes place without volume change. Temperature gradients within the catalyst are negligible.

Furthermore, the following rate equation was used:

$$
\frac{d c}{d t}=-k_{e f f} \cdot c
$$

By using a rate constant related to the catalyst mass $\left(k_{\text {eff }}^{m}\right)$,

$$
k_{e f f}^{m}=\frac{k_{e f f}}{m_{c a t}}
$$

the rate equation changes to:

$$
\frac{d c}{d t}=-k_{e f f}^{m} \cdot m_{c a t} \cdot c
$$


By separation of the variables and using the integration limits $\left(c_{0}=\right.$ concentration at reactor inlet, $c_{A}=$ concentration at reactor outlet, $\tau=$ residence time)

$$
c(t=0)=c_{0} \text { and } c(t=\tau)=c_{A}
$$

with $\left(\dot{V}_{R}=\right.$ volumetric flow at reaction conditions)

$$
\tau=\frac{V_{R}}{\dot{V}_{R}}
$$

the following expression was obtained:

$$
\ln \left(\frac{c_{0}}{c_{A}}\right)=k_{e f f}^{m} \cdot m_{c a t} \cdot \frac{V_{R}}{\dot{V}_{R}}
$$

After inserting

$$
\frac{c_{0}}{c_{A}}=\frac{1}{1-U} \text { and } \dot{V}_{R}=\frac{p_{1} \cdot \dot{V}_{1} \cdot T_{R}}{T_{1} \cdot p_{R}}
$$

and rearranging, the following equation was obtained:

$$
k_{\text {eff }}^{m}=\ln \left(\frac{1}{1-U}\right) \cdot \frac{p_{1} \cdot \dot{V}_{1} \cdot T_{R}}{T_{1} \cdot p_{R} \cdot m_{c a t} \cdot V_{R}}
$$

All concentrations used to calculate the conversion $(U)$ were average values over 5 min, which were determined after a stable concentration level was achieved.

In the lower temperature range, the plot yields a straight line for both catalysts, as can be seen on the right hand side of Figure 13. This implies that the assumption of a pseudo first order reaction was reasonable. At higher temperatures (above $700 \mathrm{~K}$ ), there were also straight lines, but with a smaller absolute value of the slope. The rate constants, which result from the right part of the plot, were nearly twice as high as those from the left part. This observation can be explained by the occurrence of mass transfer limitation. Therefore, the left part of the plot was not considered further.

Figure 13. Arrhenius plots of honeycomb catalysts (fresh and used).

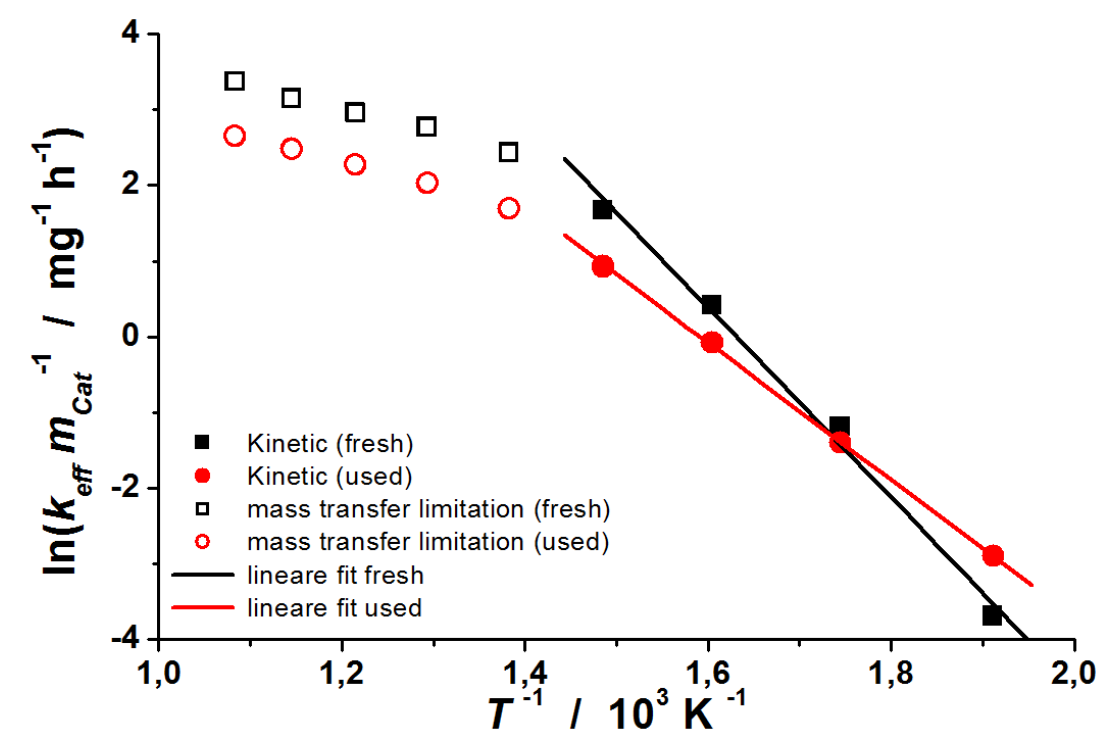


The experimental parameters, pre-exponential factors and the apparent activation energies (calculated from the right part of the Arrhenius plot) for both catalysts are listed in Table 1. The pre-exponential factor was reduced after usage in the RFS-TKI. This finding can be explained by loss of catalytic surface area due to the formation of larger noble metal crystallites out of smaller ones. The fluctuations in the exhaust gas temperature represent a particularly high stress on catalysts and can lead to a significant reduction of the active surface.

The apparent activation energy of the used catalyst was also reduced. One explanation for this is the formation of $\mathrm{PdO}$ from $\mathrm{Pd}$ during the stove experiments. $\mathrm{Pd} / \mathrm{PdO}$ is believed to be an active species for the total oxidation of methane [11].

Table 1. Experimental parameters of both catalysts.

\begin{tabular}{lllll}
\hline Parameter & Symbol & Unit & Fresh honeycomb & Used honeycomb \\
\hline Catalyst mass & $m_{\text {cat }}$ & $\mathrm{g}$ & 8.2 & 7.8 \\
Catalyst diameter & $r$ & $\mathrm{~m}$ & 0.0027 & 0.0027 \\
Catalyst length & $l$ & $\mathrm{~m}$ & 0.0024 & 0.0023 \\
Catalyst volume & $V_{R}$ & $\mathrm{~m}^{3}$ & $1.37 \times 10^{-5}$ & $1.32 \times 10^{-5}$ \\
Standard volumetric flow & $\dot{V}_{1}$ & $\mathrm{~m}^{3} \mathrm{~h}^{-1}$ & 0.501 & 0.501 \\
Activation energy & $E_{A}$ & $\mathrm{~kJ} \mathrm{~mol}^{-1}$ & 104 & 75 \\
Pre-exponential factor & $k_{\text {effm }, 0}$ & $\mathrm{~h}^{-1} \mathrm{mg}^{-1}$ & $7.756 \times 10^{8}$ & $1.778 \times 10^{6}$ \\
\hline
\end{tabular}

In addition to the permanent blocking of active sites by gaseous components (catalyst poisoning), either liquid or solid particulate matter can also lead to a reversible blocking of active sites (clogging). A loss of active surface or the blocking of active sites leads to a reduction in the activity of the catalyst. To understand the exact mechanism of the deactivation, more detailed studies are planned.

A further target of catalyst analysis is the determination of the activity in relation to the inner surface of the active species or catalyst mass to obtain conclusions regarding the most efficient catalyst composition. Then, an assessment can be given with respect to the efficient use of resources, as well as economic aspects. Therefore, it is intended to further cooperate and interact with catalyst manufacturers and researchers dealing with catalysis.

\section{Experimental Section}

For the testing of catalysts regarding their behavior and effect in biomass combustion flue gases, retrofit systems combined with several wood log stoves as well as small pellet burners are used at the Deutsches Biomasseforschungszentrum (DBFZ). In addition, a catalyst testing apparatus is available to investigate probes under defined conditions with selected gases, like methane and propane. The intent behind the work is to develop practical solutions. Therefore, the focus is on the analysis of real conditions and the measurement of a number of relevant compounds. A detailed investigation of the overall reactions that occur cannot be undertaken, due to the complex system, which includes several decomposition, oxidation and pollutant formation mechanisms. 


\subsection{Retrofit System and Wood Log Stove}

The results described were obtained during the operation with a wood log stove in combination with a retrofit system. A double-walled wood log stove "Zeus/Odin" from the brand CAMINOS with a heat output of $7 \mathrm{~kW}$ was used, which was purchased from a local construction store, i.e., it is a stove in the lower price category. The self-constructed retrofit system is used for the catalytic treatment of flue gases from wood log stoves at the DBFZ. The bypass can ensure safe operation, even in the case of catalyst blocking. The system includes a heat transfer zone to increase the heat output and is called RFS-TKI. In Figure 14, the setup of the system is illustrated. Furthermore, another retrofit system named "KATI" exists at the DBFZ for which results have already been published in [2].

Figure 14. Schematic illustration of the combination of wood log stove and retrofit system RFS-TKI.

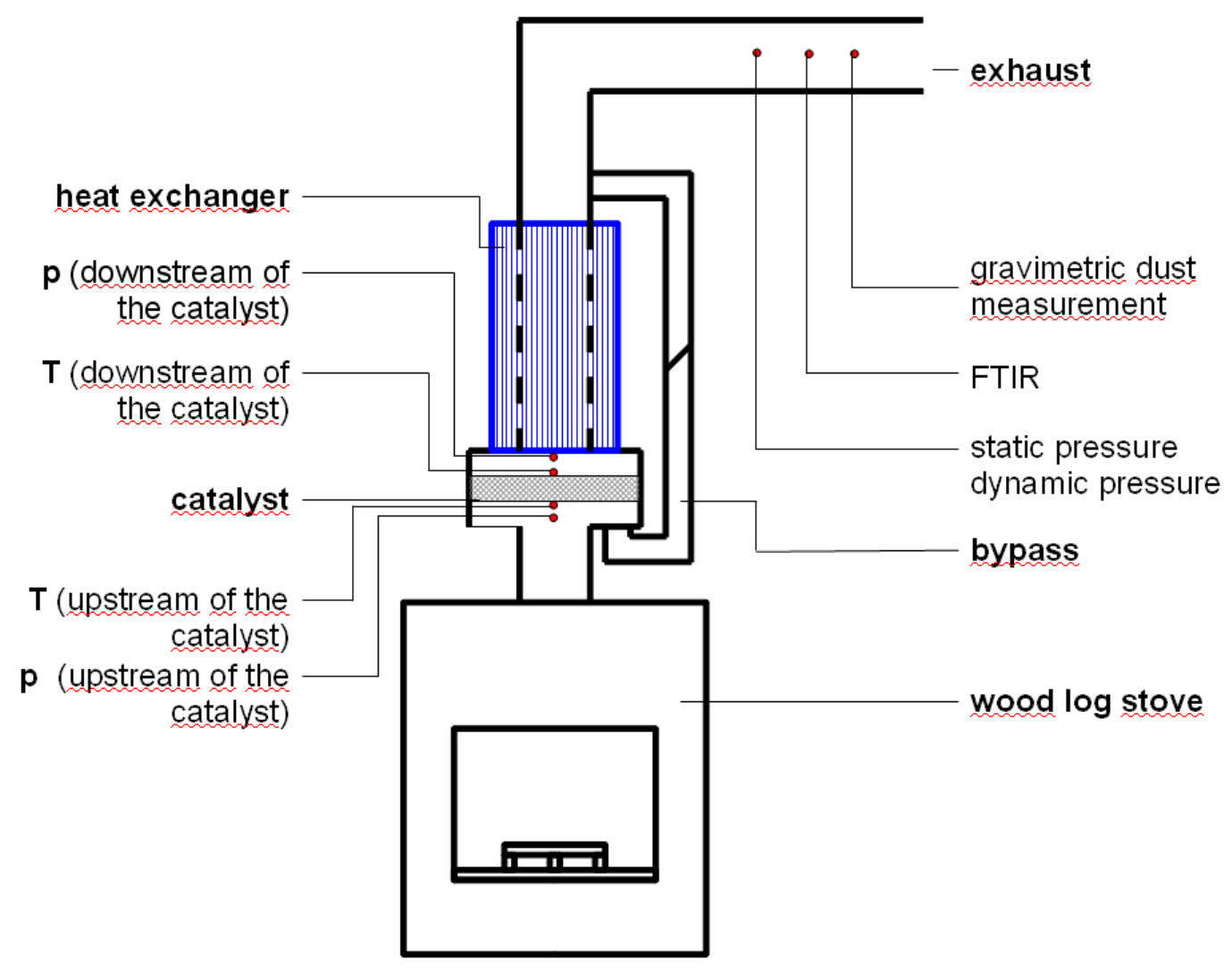

Standardized wood logs [12] were used as fuel during the experiments. The measurement of temperature and pressure inside the retrofit system and flue gas pipes were carried out with type $\mathrm{K}$ thermocouples and differential pressure sensors (type SDP 1000-L025, Manufacturer: SENSIRION) combined with Prandtl probes. The concentration of the released gaseous emissions: $\mathrm{CO}, \mathrm{CH}_{4}, \mathrm{NO}_{\mathrm{x}}$ and $\mathrm{SO}_{2}$, as well as VOCs like formaldehyde or BTX, were continuously measured using Fourier transform infrared spectroscopy (FTIR, Manufacturer: Calcmet). Also, a paramagnetic Oxygen-Analyzer (Manufacturer: M\&C, type: PMA 100) and a flame ionization detector (FID, Manufacturer: Mess- \& Analysentechnik GmbH, type: Thermo-FID ES) were used to measure oxygen and total 
volatile organic carbon compounds. The total particulate matter concentration in the flue gas was determined according to the VDI 2066/1 with gravimetric measurement.

For interpretation of the experiments, the following compounds and sum parameter given in Table 2 were analyzed. The chosen substances are relevant, due to their role in the combustion process or pollutant formation mechanism, as well as their environmental effects and other effects harmful to health. The concentration of carbon monoxide and oxygen are indicators of combustion quality. The sum parameter "aromatics" includes several compounds with one or two aromatic rings, such as benzene, acenaphthene and naphthalene. Aromatic and aliphatic compounds like acetylene are believed to be precursors of soot. The analysis of the particulate matter concentration is important in respect of two potential emerging processes. One is a possible reduction of PM that can be achieved by oxidation of soot particles as well as precursors of soot. The second is a possible filter effect of catalyst units. This second one is an unwanted effect, because it can lead to blockage of pores and active sites of the catalyst.

Table 2. Analyzed compounds and sum parameters.

\begin{tabular}{l} 
Carbon monoxide $(\mathrm{CO})$ \\
Total hydrocarbons (THC) \\
Methane $\left(\mathrm{CH}_{4}\right)$ \\
Acetylene $\left(\mathrm{C}_{2} \mathrm{H}_{2}\right)$ \\
Aromatics \\
Nitrogen oxides $\left(\mathrm{NO}_{\mathrm{X}}\right)$ \\
Oxygen $\left(\mathrm{O}_{2}\right)$ \\
Particulate matter $(\mathrm{PM})$ \\
\hline
\end{tabular}

All experiments were performed according to a defined routine to generate comparable data. The experimental routine was defined to measure application-oriented conditions for stove operation. At first, two burning cycles were performed to ignite the fire and heat up the stove. Then five burning cycles followed, which were used to measure the described process parameters and flue gas components. One burning cycle lasts for $35 \mathrm{~min}$ and may be sub-divided into the following three phases: heating up (10 min), high temperature combustion (10 $\mathrm{min}$ ) and smoldering (15 min). Total flame extinction and cooling of the stove in the smoldering phase is avoided by the given routine, because it leads to an ineffective state, where high pollutant concentrations are emitted. Average values of the burning cycles were determined for interpretation and comparison of the experiments. The given data in the chapter "Results and discussion" include average values of all five burning cycles. The concentrations are based on the natural oxygen content and dry state of the exhaust gas.

Two different catalyst types were tested in the experiments with the wood log stove, which primarily differ in their supporting material. More precisely, honeycomb and knitted wire supports have been tested. The applied noble metal catalysts, out of Pt and $\mathrm{Pd}$ on $\gamma-\mathrm{Al}_{2} \mathrm{O}_{3}$, were provided by Heraeus Precious Metals GmbH \& Co. KG. Further detailed information about the catalysts is not disclosed, in accordance with the cooperation agreement. The honeycomb support consists of cordierite. The knitted metal wire is made out of special high alloy steel.

For installation in the RFS-TKI, the catalyst units were wrapped with a high temperature resistant felt consisting of $\mathrm{SiO}_{2}, \mathrm{Al}_{2} \mathrm{O}_{3}$ and $\mathrm{ZrO}_{2}$ to seal the space between catalyst and flue gas pipe. The size of 
the two different catalyst units was determined, according to the generated pressure drop. Primarily, the secure use of catalysts is limited by their pressure drop, since an excess pressure in the firing systems has to be prevented.

The influences of volume as well as activity loss during several burning cycles of the honeycomb catalysts were examined. For comparison, the operation of the knitted wire catalyst plus the combination of honeycomb and knitted wire catalyst were examined. The emissions of the stove without using a catalyst were measured as reference values. In Table 3 the different versions examined are listed.

Table 3. Overview of the different versions for the examination.

\begin{tabular}{ll}
\hline Version & Catalyst arrangement for experiment \\
\hline 1 & Reference without catalyst \\
2 & One fresh knitted wire unit \\
3 & One fresh honeycomb unit \\
4 & Two honeycomb units (fresh) \\
5 & Two used honeycomb units (both used before the experiment for 14 burning \\
& cycles, equivalent 490 min) \\
6 & Combination of one knitted wire and one honeycomb unit (both used before for \\
& 7 burning cycles, equivalent 245 min) \\
\hline
\end{tabular}

\subsection{Catalyst Testing Apparatus}

The catalyst testing apparatus (CTA) comprises equipment used for the comparison and quantification of the activity of catalysts. Basically, the CTA consists of a fused silica reactor [13], a tube furnace, a connection for test gas cylinders, a connection for compressed air, mass flow controllers, a gas inlet pipe system and a 1311 Fast Response Triple-gas Monitor (FRTM). The FRTM allows the simultaneous measurement of carbon dioxide, oxygen and a specified hydrocarbon concentration in a gas flow. The measurement principles are based on photo-acoustic spectroscopy (for carbon dioxide and hydrocarbons) and magneto-acoustic spectroscopy (for oxygen).

Figure 15 shows a schematic drawing of the CTA. The gas inlet pipe system is built up of PFA-tubes coupled by compression fittings out of stainless steel. The mass flow controllers are purchased from Bronkhorst and the FRTM from Innova AirTech Instruments.

Cylindrical units with a diameter of $27 \mathrm{~mm}$ have been removed from the catalysts for installation of the samples under examination in the testing apparatus. To prevent any bypass flow, a high temperature resistant felt, consisting of $\mathrm{SiO}_{2}, \mathrm{Al}_{2} \mathrm{O}_{3}$ and $\mathrm{ZrO}_{2}$, was used to seal the space between the samples and the reactor wall. The volumetric gas flows of air and methane were kept constant for all experiments. The methane concentration was adjusted to $1500 \mathrm{ppm}$. The procedure on the CTA was implemented in line with the experiments on the retrofit systems. A comparison with reference to the catalyst volume is possible, considering the catalyst as a unit consisting of support, washcoat and catalytic active substance. 
Figure 15. Schematic illustration of the catalyst testing apparatus.

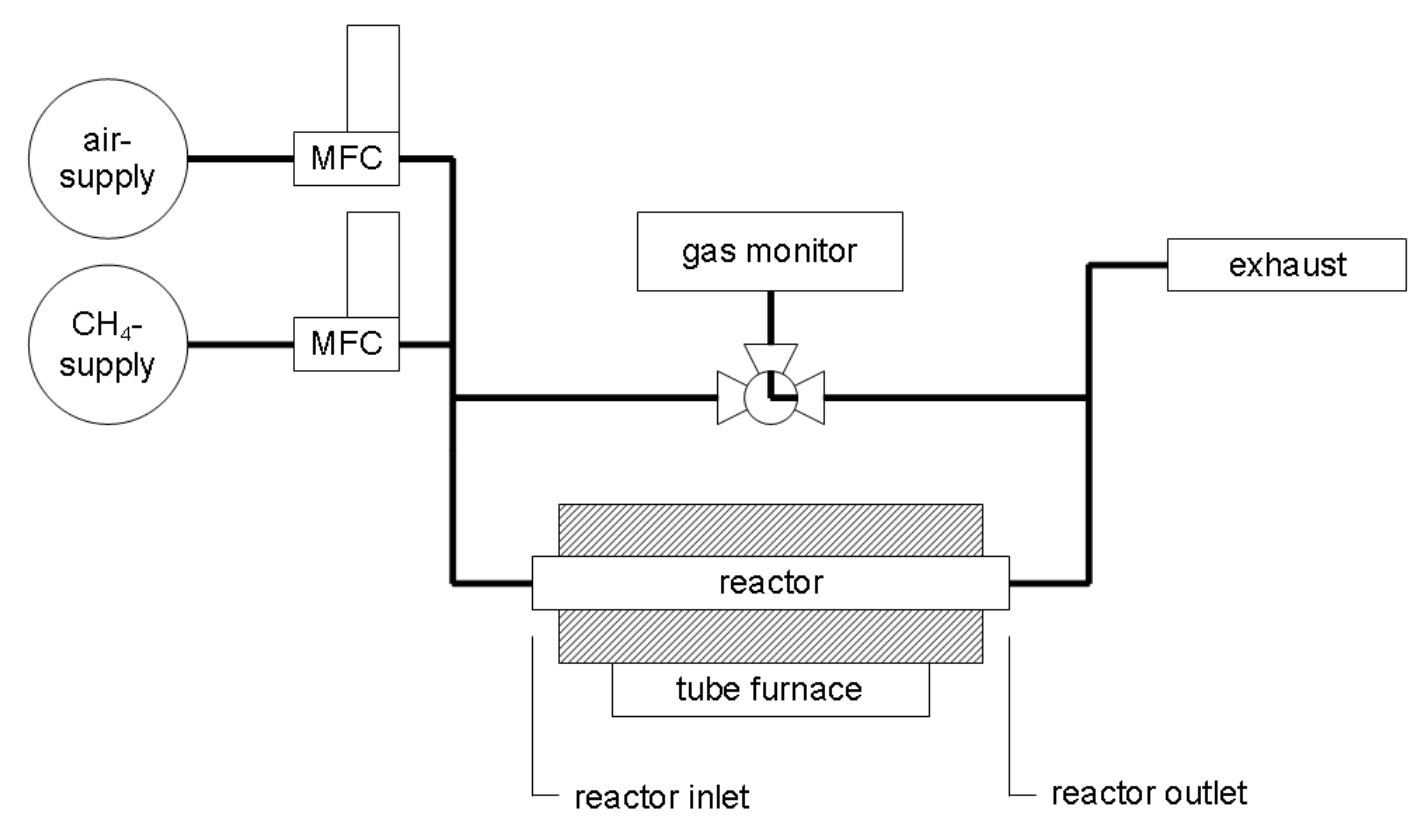

\section{Conclusions and Outlook}

The results obtained with the selected catalysts in a wood log stove demonstrate their potential for emission reduction. In particular, a significant reduction of carbon monoxide and organic carbon is possible. Even the emission of carbon compounds with a more stable structure like aromatics and methane can be reduced to some extent. The highest reduction of $99.5 \%$ for $\mathrm{CO}$ was observed using the fresh knitted wire catalyst. Also, the highest nitrogen oxide concentration was measured for this setup. Contrary to these results, higher conversions of aromatic and total hydrocarbon compounds were obtained by using the honeycomb catalyst. The emission reduction was $89.1 \%$ for total hydrocarbons and $86.3 \%$ for aromatics in the experiment with a single fresh unit. Only the reduction of methane and the formation of nitrogen oxides decreased during the performed experiments, therefore indicating a deactivation of the catalytic material. The decline of the increased emission of nitrogen oxides with catalysts observed after several hours of use can be stated certainly as a positive effect of deactivation. The activity for catalytic oxidation of carbon monoxide as well as aromatics appears not to be affected from the deactivation process observed for methane.

The analysis of the honeycomb catalyst samples with the catalyst testing apparatus confirm the results with the wood log stove and retrofit system. The deactivation of the catalytic activity for the oxidation of methane is shown after short use in biomass flue gas. In the process, the effect of decreasing activation energy after usage does not weigh the loss of catalytic surface area. According to the results, a differentiated analysis has to be done on deactivation processes of catalysts. Therefore, the use of other model gases, such as propane and carbon monoxide is planned with the catalyst testing apparatus.

However, in terms of the implementation of a comprehensive solution for catalytic emission reduction in biomass flue gases, no satisfying long-term stability can be assured so far for the catalysts under analysis. It has to be mentioned, though, that the samples are not specifically fabricated for use in biomass flue gases. In this context, the influence of a pretreatment for the catalysts is relevant. It has 
to be analyzed if a stable activity level is reached after a certain extent of deactivation, or if a total activity loss is reached after several hours of operation. Finally, the investigations have to be extended to intervals related to the heating periods of firing systems.

Currently, and in the future, analysis of other supporting materials and also other catalytic substances are being (will be) carried out to identify the most suitable catalyst arrangement. Metal foams can be an alternative to the analyzed supporting materials used so far, and metal oxides have the potential to replace noble metal-based catalysts. Lower costs of a catalytic device may be achieved with the use of metal oxides, considering the market price of noble metals. Investigations have to be carried out regarding the catalytic active surface and the amount of the used catalytic material per unit volume of the catalyst to provide a more comprehensive comparison of the different materials.

\section{Acknowledgments}

This article was written in context of the competence group "Catalytic Emissions Reduction" at the DBFZ (Deutsches Biomasseforschungszentrum gemeinnützige $G m b H$ ), supported by the Bundesministerium für Ernährung, Landwirtschaft und Verbraucherschutz of the Federal Republic of Germany.

\section{References}

1. Lenz, V.; Kaltschmitt, M. Erneuerbare Energien. BWK Das Energie-Fachmagazin 2011, 63, 42-55.

2. Bindig, R.; Hartmann, I.; Koch, C.; Matthes, M.; Schenker, M.; Thiel, C.; Kraus, M.; Roland, U.; Einicke, W.-D. Abgasreinigung an Biomassekleinfeuerungsanlagen und experimentelle Untersuchungen zur Kombination von katalytischen und elektrostatischen Abgasreinigungsverfahren. Chem. Ing. Tech. 2011, 83, 2105-2120.

3. Ahlström-Silversand, A.F.; Odenbrand, C.U.I. Thermally sprayed wire-mesh catalysts for the purification of flue gases from small-scale combustion of bio-fuel Catalyst preparation and activity studies. Appl. Catal. A 1997, 153, 177-201.

4. Carnö, J.; Berg, M.; Järas, S. Catalytic abatement of emissions from small-scale combustion of wood: A comparison of the catalytic effect in model and real flue gases. Fuel 1996, 75, 959-965.

5. Ferrandon, M.; Berg, M.; Björnbom, E. Thermal stability of metal-supported catalysts for reduction of cold-start emissions in a wood-fired domestic boiler. Catal. Today 1999, 53, $647-659$.

6. moreCat GmbH. Metal Catalysts. Available online: http://www.morecat.de/start\%20EN/index.html (accessed on 7 December 2011).

7. Dr. Pley Environmental GmbH. Saubere Energie aus Biomasse. Available online: http://www.chimcat.com/chimcat (accessed on 7 December 2011).

8. Gs-components handelsgesmbH. Firecat. Available online: http://www.firecat.cc/html/english.html (accessed on 7 December 2011).

9. Heidenreich, S.; Nacken, M.; Hackel, M.; Schaub, G. Catalytic filter elements for combined particle separation and nitrogen oxides removal from gas streams. Powder Technol. 2008, 180, 86-90. 
10. Ozil, F.; Tschamber, V.; Haas, F.; Trouvé, G. Efficiency of catalytic processes for the reduction of $\mathrm{CO}$ and VOC emissions from wood combustion in domestic fireplaces. Fuel Process. Technol. 2009, 90, 1053-1061.

11. Farrauto, R.J.; Hobson, M.C.; Kennelly, T.; Waterman, E.M. Catalytic chemistry of supported palladium for combustion of methane. Appl. Catal. A 1992, 81, 227-237.

12. Hartmann, I.; Lenz, V.; Schenker, M.; Thiel, C.; Roland, U.; Einicke, W.-D.; Bindig, R. Katalysatoruntersuchungen an einer Technikumsanlage für Biomasse-Kleinfeuerungen. Chem. Ing. Tech. 2011, 83, 1-7.

13. Bindig, R.; Hartmann, I.; Thiel, C. Apparatus for identification of applicable catalysts for exhaust gas purification at small-scale biomass combustion systems. In Proceedings of the IBC LEIPZIG—International Biomass Conference, Leipzig, Germany, May 2011.

(C) 2012 by the authors; licensee MDPI, Basel, Switzerland. This article is an open access article distributed under the terms and conditions of the Creative Commons Attribution license (http://creativecommons.org/licenses/by/3.0/). 